\title{
The relationships between structural and functional diversity within and among macrophyte communities in lakes
}

\author{
Rafał CHMARA, Józef SZMEJA, Krzysztof BANAŚ \\ Department of Plant Ecology, University of Gdańsk, Wita Stwosza 59, 80-308 Gdańsk, Poland \\ ${ }^{*}$ Corresponding author: rafal.chmara@biol.ug.edu.pl
}

\begin{abstract}
We studied the relationships between structural and functional diversity within and among macrophyte communities of softwater lakes. Diversity was assessed based on Simpson's diversity index (SD), species richness (S), Rao's functional diversity (FD ${ }_{\mathrm{Q}}$ ) and shared plant traits along a gradient of $\mathrm{pH}$. A total of 10,800 cover-plant samples (area $=0.1 \mathrm{~m}^{2}$ ) were analysed, collected from 241 sections of the bottom (with a depth resolution of $1.0 \mathrm{~m}$ ) of 38 lakes in Poland. We identified 59 species of macrophytes and recognized four communities. Along a gradient of increasing $\mathrm{pH}$ we found i) an increase of species richness; ii) a uniformity of abundance in communities; and iii) an increase in the quantitative contribution of life history traits such as perennials, submerged anchoring, leaf placement along an orthotropic shoot and generative reproduction. On the other hand, there was a decrease in unanchored and evergreen perennials. In our study, we found that the variety of these traits within communities is greater than that between them. Within lakes, structural diversity was low, whereas it was high between lakes. Functional diversity exhibited an opposite pattern: it was high at lake scale, and low between lakes. A combination of partitioning diversity and utilizing environmental variables significantly improves the prediction of community structure and the conservation of lakes.
\end{abstract}

Key words: $\alpha$ - and $\beta$-diversity; macrophyte communities; oligotrophic lakes; life history traits; diversity partitioning.

Received: February 2017. Accepted: September 2017.

\section{INTRODUCTION}

Submerged plant species are not homogeneously distributed in lakes. Understanding how and why species diversity changes across different spatial scales remains an important task facing contemporary ecology (Levin, 1992; Petchey and Gaston, 2002; Ricklefs, 2004) and the ecology of lakes in particular (Murphy, 2002). Elucidating patterns of diversity has many uses, from the identification of species composition to predicting how regional and local environmental changes will affect diversity at different levels of organization.

Softwater lakes represent an important component of the diversity in northern, northwestern and north-central parts of Europe, particularly in Fennoscandia, the British Isles, Denmark, the Netherlands, northern Germany and northern Poland at latitudes of $50-70^{\circ} \mathrm{N}$ and longitudes of $10^{\circ} \mathrm{W}-35^{\circ} \mathrm{E}$ (Murphy, 2002). These lakes are poor in calcium $\left(<3 \mathrm{mg} \mathrm{Ca} \mathrm{L}^{-1}\right)$ and nutrients, acidic or neutral, and often typified by carbon-limited hydrophytes (Madsen and Sand-Jensen, 1991; Pedersen et al., 1995). Their plant community diversity varies from low to moderately high. Overall, these lakes support a range of freshwater plant communities that are rare in Europe and a number of very rare plant species, particularly isoetids (Rørslett, 1991; Pulido et al., 2012, 2015). In this group of lakes, an important factor differentiating plant communities is the water acidity/alkalinity (Vestergaard and Sand-Jensen, 2000; Chmara et al., 2014).

In northwestern Poland softwater lakes $(\mathrm{pH}$ range $=4.0-7.1$ ) are characterized by a predominance of mosses, isoetids and neutrophytic vascular plants and a very low presence in $\mathrm{pH}$-neutral lakes of charophytes in contrast to hardwater lakes $(\mathrm{pH}>7.1)$, where the vegetation structure is dominated by charophytes (Bociąg et al., 2013; Chmara et al., 2014). Peatland lakes are the most acidic and are dominated by a moss carpet (Szmeja, 2010), which is formed mostly by perennial and evergreen mosses that absorb nutrients from water (Riis et al., 2010). Isoetids, occurring in less acidic lakes, are perennial and evergreen, but in contrast to mosses can absorb nutrients from the sediment. They have a well-developed root system (Szmeja, 1987; Szmeja and Gałka, 2008) and extensive air channels allowing efficient intra-plant transport of $\mathrm{CO}_{2}$ and $\mathrm{O}_{2}$ between roots and leaves. As a result, most $\mathrm{CO}_{2}$ needed for photosynthesis is derived from the sediment (Søndergaard and Sand-Jensen, 1979) rather than from the lake water. Isoetids are stress-selected plants (Grime, 1977) with the lowest growth and decomposition rates among aquatic species (Nielsen and Sand-Jensen, 1991). The least acidic softwater lakes are predominantly occupied by neutrophytic vascular plants and by smaller populations of charophytes.

In lakes with minor signs of human pressure, 
submerged plants form communities wherein species interactions dominate over dispersal dynamics to form a highly zoned structure (Chmara et al., 2013). This means that the $\alpha$-diversity level need not refer to the whole lake but, rather, to its bottom sections (i.e., depth zones). In turn, the $\beta$-level can be equated with diversity among communities. Chmara et al. (2015) proposed a way to distinguish $\alpha$ - and $\beta$-diversity levels in lakes and demonstrated that along a gradient of increasing $\mathrm{pH}$ (4.0 to 7.1 ), the diversity of a community increases and share of life history traits and the species composition are subject to significant change. Evergreen, unanchored and plagiotropic plants with small leaves (i.e., mosses) are replaced by evergreen, rosette forms, which are replaced by charophytes and vascular plants, especially pondweeds.

Plant functional diversity, like species richness, is an important attribute of a community (Díaz and Cabido, 2001; Petchey and Gaston, 2002, 2006). Both of these traits are useful for analysis across multiple spatial scales and along environmental gradients (Boutin and Keddy, 1993; de Bello et al., 2006). Firstly, we evaluated structural and functional diversity of macrophyte communities along acidity gradient on different spatial scales. Secondly, we addressed two questions: What are quantitative relationships between structural and functional diversity on the spatial scale? Is the variety of plant traits in communities greater at $\alpha$-diversity than at $\beta$-diversity level?

\section{METHODS}

\section{Experimental design}

These studies were conducted in 38 oligotrophic softwater lakes situated along the southern coast of the Baltic Sea in NW Poland. During the years 2010-2013 (from July to August), we collected 10,800 cover-plant samples (the coverage of each species in the sample with the area of $0.1 \mathrm{~m}^{2}$ ) from well-preserved lakes (i.e., those without clear signs of human pressure); each lake was sampled only once. Investigated sites included 10 peatland lakes with moss carpet community (1300 coverplant samples), 13 lakes with isoetids and acidophytic mosses (3400), 11 lakes with isoetids and neutrophytic mosses (4300), and four lakes with neutrophytic vascular plants and charophytes (1800; Supplementary Tab. 1). Using the TWINSPAN algorithm (Hill and Šmilauer, 2005), based on the previous results (Chmara et al., 2015) we chose four macrophyte communities:

1) Moss carpet: it covers the bottom of highly acidic and calcium-poor peatland lakes. It consists predominantly of mosses, especially Sphagnum denticulatum Brid. and Warnstorfia exannulata (Schimp.) Loeske while vascular plants are rare and charophytes are never found. In this community, 17 species occur; one of them ( $S$. denticulatum) is an absolute dominant.

2) Isoetids with acidophytic mosses: they occupy less acidic lakes and consist of a larger number of species (27), none of which is dominant. The highest frequency of occurrence is found for vascular plants, followed by acidophytic mosses and sporadic charophytes. The co-dominants are Isoëtes lacustris L. and S. denticulatum (40.6\%); Lobelia dortmanna L. and $W$. exannulata occur less frequently and with lower abundance.

3) Isoetids with neutrophytic mosses: they occur in moderately acidic lakes (median pH 6.3; Tab. 1) with almost double the calcium concentration $\left(5.7 \mathrm{mg} \mathrm{L}^{-1}\right)$ and water conductivity $\left(57.3 \mu \mathrm{S} \mathrm{cm} \mathrm{cm}^{-1}\right)$. In this community, 37 species occur, none of which is dominant but as many as three are co-dominant ( $I$. lacustris, Myriophyllum alterniflorum DC. and Drepanocladus sordidus (Müll. Hal.) Hedenäs). The highest frequency is observed for vascular plants, followed by mosses and, importantly, charophytes.

4) Neutrophytic vascular plants and charophytes: they occur in lakes with the highest relative $\mathrm{pH}$ and a fairly large calcium concentration. In this community, 38 species occur, none of which is dominant but three of which (M. alterniflorum, Elodea canadensis Michx. and Chara virgata Kützing) are co-dominant. The highest frequency is observed for vascular plants, especially $M$. alterniflorum and E. canadensis; less common are charophytes, mainly $C$. virgata $(11.9 \%)$; mosses occur occasionally.

In the lakes, we observed 59 species of submerged macrophytes, including 36 vascular plants, 12 bryophytes, nine charophytes and two liverworts. Plant names follow the guidelines of The Plant List (2013), charophytes according to Krienitz and Nowak (2016).

\section{Sampling design}

Macrophytes were sampled along bottom sections in transect, perpendicular to the shoreline. The bottom sections were the parts of the bottom defined by isobates at 1-m intervals from 0 to the maximum depth of macrophyte occurrence $(11 \mathrm{~m})$. For each cover-plant sample (squares with sides $=0.33 \mathrm{~m}$, and area $=0.1 \mathrm{~m}^{2}$ ) we estimated the coverage of each species. Samples were collected from 241 bottom sections, each of which had a length of $250 \mathrm{~m}$ and were parallel to the lakeshore. The number of cover-plant samples in the lake depended on the number of bottom sections and macrophytes frequency (Supplementary Fig. 1). The samples were collected by SCUBA diving.

Moreover, 241 500-mL water samples were collected in the depth zones. Environmental conditions in the depth zones were described in terms of water $\mathrm{pH}$, conductivity 
( $\left.\mu \mathrm{S} \quad \mathrm{cm}^{-1}\right)$, calcium concentration $\left(\mathrm{mg} \mathrm{L} \mathrm{L}^{-1}\right)$, total phosphorus $\left(\mathrm{mg} \mathrm{L}^{-1}\right)$ and total nitrogen $\left(\mathrm{mg} \mathrm{L}^{-1}\right)$. Water properties about $0.3-0.5 \mathrm{~m}$ above the sediment were determined, depending on the height of the plants forming the underwater community, but generally, a sample of water was taken above the plants or in the dominant macrophyte patches. To each lake, one dominant community has been assigned, and the water properties found in all depth zones describe the environmental conditions of the community in this lake. Water properties just above the sediment within a given community are provided in Tab. 1. Water electrolytic conductivity and $\mathrm{pH}$ were measured using a multiparameter device YSI 650 MDS with probe $6600 \mathrm{~V} 2$. Water calcium concentration was analysed by a complexometric method with a versenate solution in the presence of calcess as an indicator (Eaton et al., 2005). Nitrogen and phosphorus were determined with photometric methods. Total nitrogen was analysed using a Spectroquant Cell Test with sulphuric acid, sodium hydroxide and potassium persulphate. Total phosphorus was analysed by a Spectroquant Phosphate Test (PMB) after the mineralization of previous water samples in a mixture of nitric and sulphuric acid $(2: 1)$ in the microwave digestion system Mars 5 CEM.

\section{Evaluation of diversity metrics}

For each community, the following indices were calculated:

i) Simpson index of diversity (SD)

$$
\mathrm{SD}=1-\sum_{i=1}^{S} p_{i}^{2}
$$

where $p_{\mathrm{i}}$ is the proportion of the $\mathrm{i}_{\mathrm{th}}$ species (i.e., $p_{\mathrm{i}}=\mathrm{N}_{\mathrm{i}} / \mathrm{N}$ and $\mathrm{N}=\Sigma \mathrm{N}_{\mathrm{i}}$ ). Originally, $\mathrm{N}_{\mathrm{i}}$ was used as the number of individuals of the $i_{\text {th }}$ species; we used species relative abundance in this study.

ii) Species richness (S)

iii) Functional diversity $\left(\mathrm{FD}_{\mathrm{Q}}\right)$, as measured by Rao's $\mathrm{Q}$.

We used easily measurable traits ("soft" traits). The calculation of $\mathrm{FD}_{\mathrm{Q}}$ takes into account four life history traits of each species: i) plant life span; ii) shoot growth form; iii) leaf distribution along the stem; and iv) reproduction (R), according to Willby et al. (2000), Kleyer et al. (2008) and the LEDA Traitbase at http://www.leda-traitbase.org. The subdivision of these traits produced a total of 14 attributes (Supplementary Tab. 2).

The $\mathrm{FD}_{\mathrm{Q}}$ index was calculated according to Rao's $\mathrm{Q}$ formula (Ricotta, 2005; Lepš et al., 2006):

$$
\mathrm{FD}_{\mathrm{Q}}=\sum_{i=1}^{S} \mathrm{i} \sum_{j=1}^{S} \mathrm{i} \mathrm{d}_{i j} \mathrm{p}_{i} \mathrm{p}_{j}
$$

$\mathrm{FD}_{\mathrm{Q}}$ is the sum of trait dissimilarity among all pairs of species weighted by species relative abundance. In the equation, $d_{i j}$ is the functional distance equal to the squared Euclidean distance between species $i$ and $j$. According to de Bello et al. (2006), our $\mathrm{FD}_{\mathrm{Q}}$ calculations were based on four life history traits as multi-traits index, but we also considered each trait separately. We created two types of matrices: (a) a species ' sample matrix, wherein we used species frequency as a measure of abundance and; (b) a species ' trait attributes matrix. Algorithms for $\mathrm{FD}_{\mathrm{Q}}$ were calculated according to Lepš et al. (2006). $\mathrm{FD}_{\mathrm{Q}}$ is constrained between 0 and 1 .

\section{Diversity partitioning}

We take into account diversity within communities ( $\alpha$ diversity level) and among them ( $\beta$-diversity level) in softwater lakes. The first level of diversity ( $\alpha$-diversity) refers in a topological sense to the bottom sections, or depth zones, whereas the $\beta$-diversity refers to the diversity among these bottom section communities. We have adopted the additive model of diversity $(\gamma=\alpha+\beta$; Whittaker, 1975; Veech et al., 2002). For $\alpha$ and $\beta$ diversity levels, we used the following metrics: species richness $(\mathrm{S})$, Simpson diversity index (SD) and $\mathrm{FD}_{\mathrm{Q}}$. We partitioned the structural and functional diversity metrics by following three steps: i) we calculated the $\alpha$-diversity for each community; ii) we calculated the $\gamma$-diversity; and

\begin{tabular}{|c|c|c|c|c|c|c|c|c|}
\hline \multirow[t]{2}{*}{ Community } & \multicolumn{4}{|c|}{ Median } & \multicolumn{4}{|c|}{ Min. - Max. } \\
\hline & $\mathbf{A}$ & B & $\mathrm{C}$ & D & $\mathbf{A}$ & B & $\mathrm{C}$ & D \\
\hline $\mathrm{pH}$ & 4.7 & 5.5 & 6.3 & 7.1 & $4.1-5.5$ & $4.2-6.0$ & $5.4-7.7$ & $5.5-7.9$ \\
\hline Conductivity $\left(\mu \mathrm{S} \mathrm{cm}^{-1}\right)$ & 30.0 & 31.4 & 57.3 & 76.1 & $17.2-66.1$ & $13.1-59.6$ & $36.1-82.3$ & $29.3-95.4$ \\
\hline $\mathrm{Ca}^{2+}\left(\mathrm{mg} \mathrm{L}^{-1}\right)$ & 1.5 & 2.2 & 5.7 & 8.8 & $1.0-3.0$ & $1.3-5.2$ & $2.4-15.3$ & $4.0-18.6$ \\
\hline $\mathrm{N}_{\text {tot }}\left(\mathrm{mg} \mathrm{L}^{-1}\right)$ & 1.2 & 1.1 & 1.3 & 1.1 & $0.6-3.5$ & $0.6-1.3$ & $0.8-2.7$ & $1.0-1.5$ \\
\hline $\mathrm{P}_{\text {tot }}\left(\mathrm{mg} \mathrm{L}^{-1}\right)$ & 0.1 & 0.08 & 0.08 & 0.09 & $0.003-0.3$ & $0.01-0.2$ & $0.04-0.1$ & $0.06-0.1$ \\
\hline
\end{tabular}

Tab. 1. Properties of water in communities.

A, moss carpet; $B$, isoetids with acidophytic mosses; $C$, isoetids with neutrophytic mosses; $D$, neutral vascular plants and charophytes. 
then iii) we computed $\beta=\gamma-\alpha$, according to de Bello et al. (2009).

\section{RESULTS}

\section{Structural diversity}

In the environmental conditions occurring in softwater lakes (Tab. 1 ), diversity within a community ( $\alpha$-diversity) and that among communities ( $\beta$-level) differ. It is worth noting that $\beta$ species richness is higher than $\alpha$ species richness (Tab. 2). The beta diversity accounted for $84.3 \%$ in all communities and ranged between $57.4 \%$ and $71.5 \%$ within each community (Tab. 2). With decreasing water acidity, in communities from $\mathrm{A}$ to $\mathrm{D}$, species richness increases at the $\alpha$-, $\beta$ - and g-diversity levels (Fig. 1a).

The $\beta$ Simpson diversity index (SD, percentage accounted) is lower than $\beta$ species richness. Moreover, the $\alpha \mathrm{SD}$ index is greater than $\beta$ SD. The proportion of $\alpha$ to $\beta$ SD varies among communities. In a moss carpet community, the Simpson diversity index calculated within the community is 0.46 and is the lowest of all communities assessed.

Macrophyte communities are characterized by high $\beta$ species richness and a high SD within communities. Moreover, under conditions of decreasing acidity, we found an increase in the number of species within a community and a uniform species abundance in the communities. Such a pattern is visible within communities ( $\alpha$-diversity level) and among them $(\beta$ diversity).

\section{Functional diversity}

In lakes ranged from very acidic to slightly alkaline, we observed a shift in the $\mathrm{FD}_{\mathrm{Q}}$ multi-traits index in communities at the $\alpha$-, $\beta$ - and $\gamma$-diversity levels (Tab. 2; Fig. 1b). The $\gamma$ functional diversity of plant communities ranged between 0.14 and 0.51 . We found higher values in each community for $\alpha \mathrm{FD}_{\mathrm{Q}}$ than for $\beta \mathrm{FD}_{\mathrm{Q}}$ (Tab. 2).

Along a gradient of decreasing lake acidity increases in the participation of the following were found (Fig. $2 \mathrm{a}-\mathrm{d}$, see $\gamma \mathrm{FD}_{\mathrm{Q}}$, solid line): i) plant life span; ii) leaf distribution (an increase in the proportion of species with leaves along an orthotropic shoot); and iii) modes of reproduction (an increasing number of species reproducing in two ways, i.e., vegetatively and generatively). Furthermore, the share of underwater anchored forms (Fig. 2b) increased, whereas

Tab. 2. The structural and functional diversity of communities (A-D) at $\alpha-, \beta$ - and $\gamma$-diversity level (\%=percentage accounted).

\begin{tabular}{|c|c|c|c|c|c|c|}
\hline & \multicolumn{3}{|c|}{ Structural diversity } & \multicolumn{3}{|c|}{ Functional diversity } \\
\hline & $\mathrm{S}$ & $\%$ & SD & $\%$ & $\mathrm{FD}_{\mathbf{Q}}$ & $\%$ \\
\hline \multicolumn{7}{|l|}{ All communities } \\
\hline$\alpha$ Range & $2-23$ & - & $0.02-0.9$ & - & $0.02-0.5$ & - \\
\hline$\alpha$ Mean & 9.3 & 15.7 & 0.68 & 74.7 & 0.32 & 64 \\
\hline$\beta$ & 49.7 & 84.3 & 0.23 & 25.2 & 0.18 & 36 \\
\hline$\gamma$ & 59 & 100 & 0.91 & 100 & 0.50 & 100 \\
\hline \multicolumn{7}{|c|}{ Community $\mathrm{A}\left(\mathrm{pH}_{\mathrm{Me}}=4.7\right)$} \\
\hline$\alpha$ Range & $2-9$ & - & $0.02-0.7$ & - & $0.02-0.2$ & - \\
\hline$\alpha$ Mean & 5 & 29.4 & 0.46 & 76.6 & 0.12 & 85.7 \\
\hline$\beta$ & 12 & 70.6 & 0.14 & 23.4 & 0.02 & 14.3 \\
\hline$\gamma$ & 17 & 100 & 0.60 & 100 & 0.14 & 100 \\
\hline \multicolumn{7}{|c|}{ Community $\mathrm{B}\left(\mathrm{pH}_{\mathrm{Me}}=5.5\right)$} \\
\hline$\alpha$ Range & $4-12$ & - & $0.4-0.8$ & - & $0.2-0.5$ & - \\
\hline$\alpha$ Mean & 7.7 & 28.5 & 0.72 & 87.8 & 0.38 & 88.4 \\
\hline$\beta$ & 19.3 & 71.5 & 0.10 & 12.2 & 0.05 & 11.6 \\
\hline$\gamma$ & 27 & 100 & 0.82 & 100 & 0.43 & 100 \\
\hline \multicolumn{7}{|c|}{ Community $\mathrm{C}\left(\mathrm{pH}_{\mathrm{Me}}=6.3\right)$} \\
\hline$\alpha$ Range & $7-22$ & - & $0.7-0.9$ & - & $0.3-0.5$ & - \\
\hline$\alpha$ Mean & 12.6 & 34 & 0.81 & 92 & 0.44 & 86.2 \\
\hline$\beta$ & 24.4 & 66 & 0.07 & 8 & 0.07 & 13.8 \\
\hline$\gamma$ & 37 & 100 & 0.88 & 100 & 0.51 & 100 \\
\hline \multicolumn{7}{|c|}{ Community $\mathrm{D}\left(\mathrm{pH}_{\mathrm{Me}}=7.1\right)$} \\
\hline$\alpha$ Range & $4-23$ & - & $0.3-0.9$ & - & $0.1-0.5$ & - \\
\hline$\alpha$ Mean & 16.2 & 42.6 & 0.73 & 82 & 0.33 & 75 \\
\hline$\beta$ & 21.8 & 57.4 & 0.16 & 18 & 0.11 & 25 \\
\hline$\gamma$ & 38 & 100 & 0.89 & 100 & 0.44 & 100 \\
\hline
\end{tabular}


that of unanchored evergreen perennials (Fig. 2a) decreased. It is worth noting that the highest $\mathrm{FD}_{Q}$ value at the $\alpha$ level in a moss carpet was found in the shoot growth form (Tab. 3) and that $\beta \mathrm{FD}_{\mathrm{Q}}$ (i.e., the variety of samples among lakes with moss carpet) had the lowest value in this community (Tab. 2). Furthermore, the highest value of $\alpha$ $\mathrm{FD}_{\mathrm{Q}}$ in isoetids with an acidophytic moss community was found for the leaf distribution along the stem (0.5), and a slightly smaller value (0.4) was obtained for shoot growth form. Interestingly, $\beta \mathrm{FD}_{\mathrm{Q}}$ had a higher value in this community than in moss carpet. The values of $\alpha \mathrm{FD}_{\mathrm{Q}}(0.3)$ and $\beta \mathrm{FD}_{\mathrm{Q}}(0.1)$ are similar to those of the previous community (Tab. 2). The $\alpha \mathrm{FD}_{\mathrm{Q}} \mathrm{s}$ for shoot growth form $(0.2)$ and leaf distribution along the stem (0.5) are smaller than those for a community of isoetids with neutrophytic mosses (Tab. 3).

\section{The relationships between structural and functional diversity}

Species richness at the $\alpha$-diversity (within community, black bars; Fig. 1a) is less than that at the $\beta$-diversity (among communities, white bars; Fig. 1a). Regarding the functional diversity of communities (Fig. 1b), the values of $\alpha \mathrm{FD}_{\mathrm{Q}}$ (black bars; Fig. 1b) are higher than those of $\beta$ $\mathrm{FD}_{\mathrm{Q}}$ (white bars; Fig. 1b). This means that the variety of plant traits in communities at the $\alpha$-diversity level is greater than that at $\beta$-diversity level.

Our results show different relationships between species richness and $\mathrm{FD}_{\mathrm{Q}}$ at the $\alpha$ - and $\beta$-diversity levels (Tab. 2; Figs. 1 and 3). This means that in lakes, the species diversity of a community ( $\alpha$-diversity) determined by species richness is low, whereas the functional diversity is high; between lakes ( $\beta$-diversity), species richness is high, while functional diversity is low. Very similar relationships we found both for four macrophyte communities (Fig. 1) as well as whole communities in lakes (Fig. 3).

Tab. 3. The $\mathrm{FD}_{\mathrm{Q}}$ for selected life history traits in communities at $\alpha$-, $\beta$ - and $\gamma$-diversity.

\begin{tabular}{|c|c|c|c|c|}
\hline \multirow[b]{2}{*}{ Life history traits } & \multicolumn{4}{|c|}{ Community } \\
\hline & $\mathbf{A}$ & B & C & D \\
\hline \multicolumn{4}{|l|}{ Plant life span } & 0.400 \\
\hline$\beta$ & 0.010 & 0.020 & 0.100 & 0.100 \\
\hline$\gamma$ & 0.050 & 0.100 & 0.500 & 0.500 \\
\hline \multicolumn{5}{|l|}{ Shoot growth form } \\
\hline$\alpha$ & 0.300 & 0.400 & 0.400 & 0.200 \\
\hline$\beta$ & 0.100 & 0.010 & 0.060 & 0.030 \\
\hline$\gamma$ & 0.400 & 0.400 & 0.500 & 0.200 \\
\hline \multicolumn{5}{|c|}{ Leaf distribution along the stem } \\
\hline$\alpha$ & 0.100 & 0.500 & 0.600 & 0.500 \\
\hline$\beta$ & 0.001 & 0.100 & 0.100 & 0.200 \\
\hline$\gamma$ & 0.100 & 0.600 & 0.700 & 0.700 \\
\hline \multicolumn{5}{|l|}{ Reproduction } \\
\hline$\alpha$ & 0.050 & 0.500 & 0.500 & 0.500 \\
\hline$\beta$ & 0.003 & 0.100 & 0.100 & 0.200 \\
\hline$\gamma$ & 0.050 & 0.600 & 0.600 & 0.700 \\
\hline
\end{tabular}
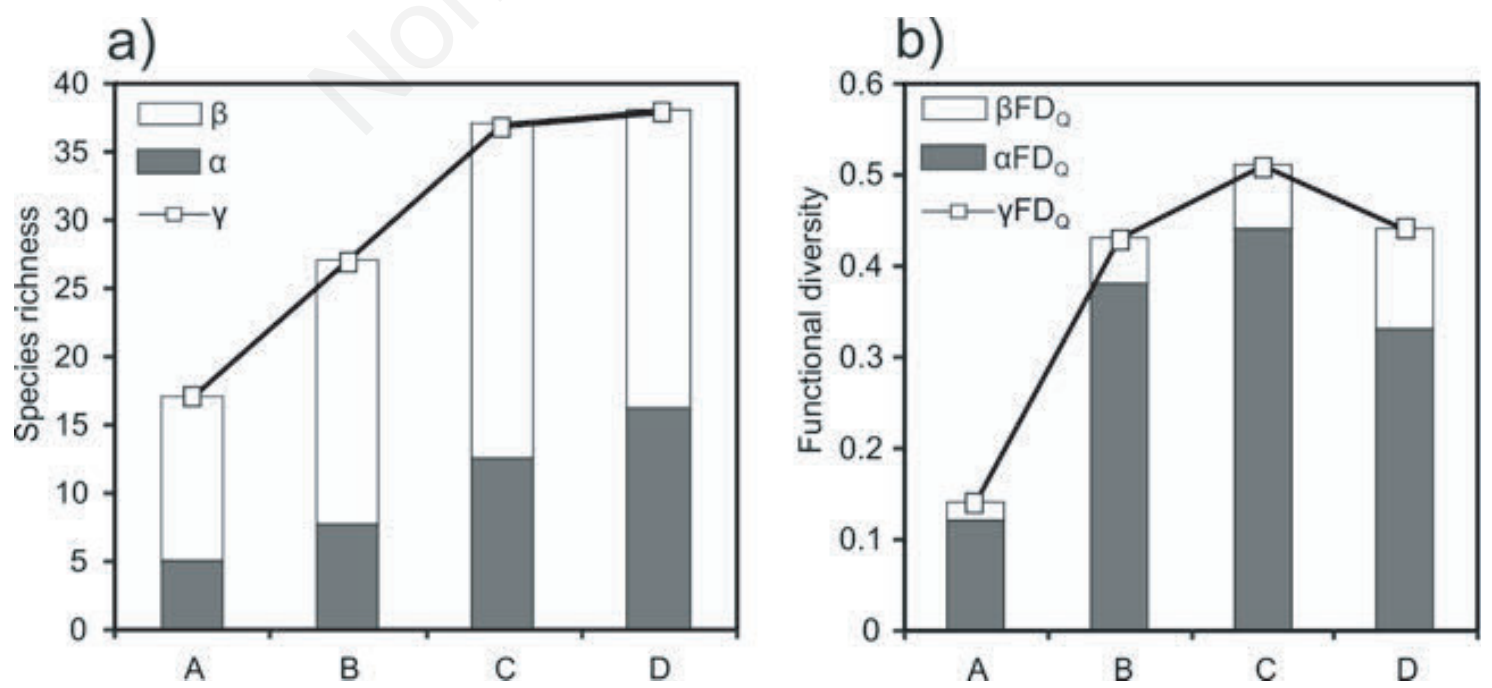

Fig. 1. Species richness (a) and $\mathrm{FD}_{\mathrm{Q}}$ index (b) for the communities A-D. A, moss carpet; $\mathrm{B}$, isoetids with acidophytic mosses; $\mathrm{C}$, isoetids with neutrophytic mosse; $D$, neutrophytic vascular plants and charophytes; $\alpha-, \beta$-, and $\gamma$ - are diversity levels: $\alpha$, within community; $\beta$, among communities; $\gamma$, total diversity of communities in lakes. 


\section{DISCUSSION}

Many previous studies reported species diversity to be related to functional diversity (de Bello et al., 2006; Hu et al., 2014). Consistently with this pattern, we evaluated structural and functional diversity of macrophyte communities and found relationships between species diversity and functional diversity. In support of the aim of the study, our results show that environmental factors such as water acidity may be responsible for a large proportion of the variance in structural and functional diversity observed among submerged plant communities. We have observed a low $\alpha$-diversity for species richness. A similarly low species richness at the $\alpha$-diversity level was found in Pyrenean lakes (Gacia et al., 2009; Chappuis et al., 2014). High regional diversity versus low local diversity (Tab. 2, Fig. 1a) can be explained by the predominance of small water bodies, which group together numerous stenoecious species and contribute to large differences between water bodies in terms of species composition (Nicolet et al., 2004; Scheffer and van Geest, 2006). Consequently, the $\beta$-diversity of softwater plant communities is high (Tab. 2). These results are consistent with the general pattern in freshwater systems (Heino, 2011). Recent studies reported that species and functional diversity of macrophyte communities depend on depth gradient of lakes (Fu et al., 2014; Bolpagni et al., 2016). Community structure and species composition are often a)

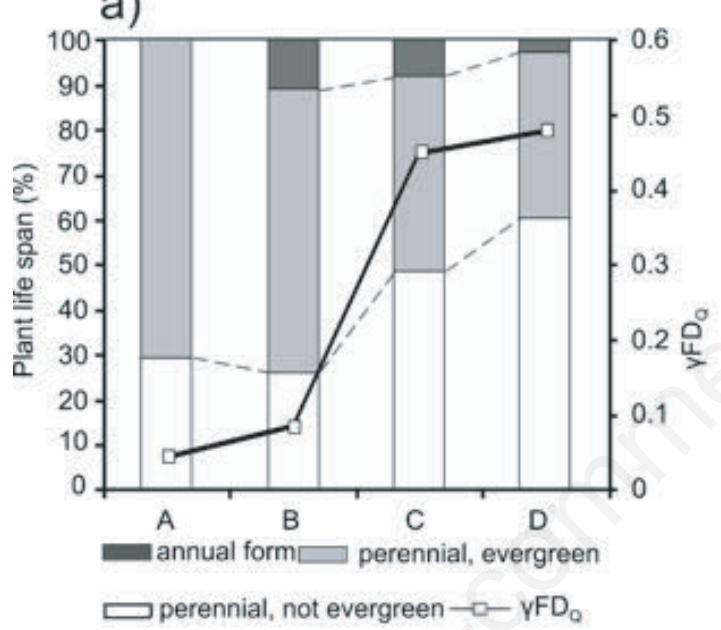

c)

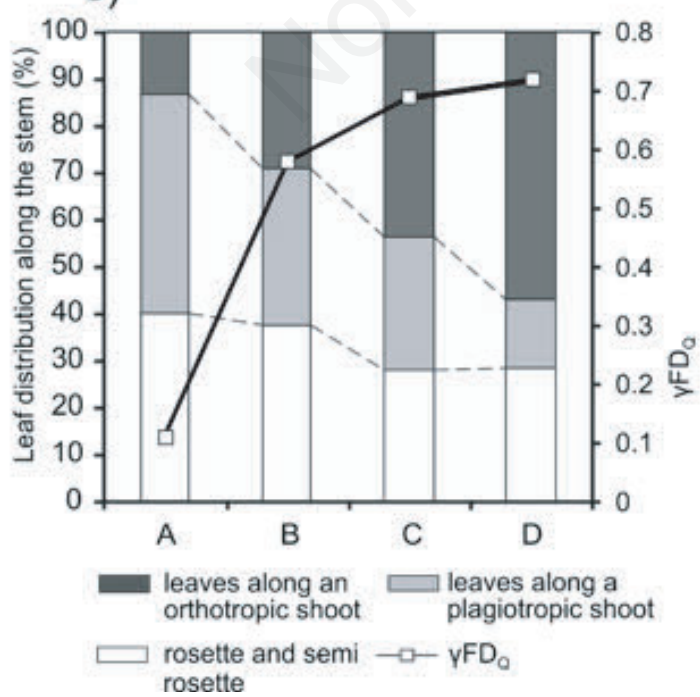

b)

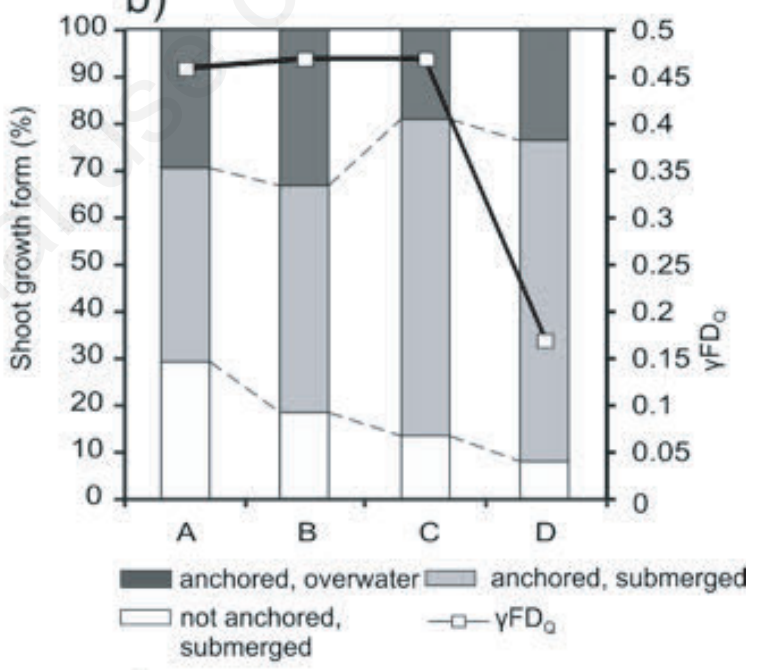

d)

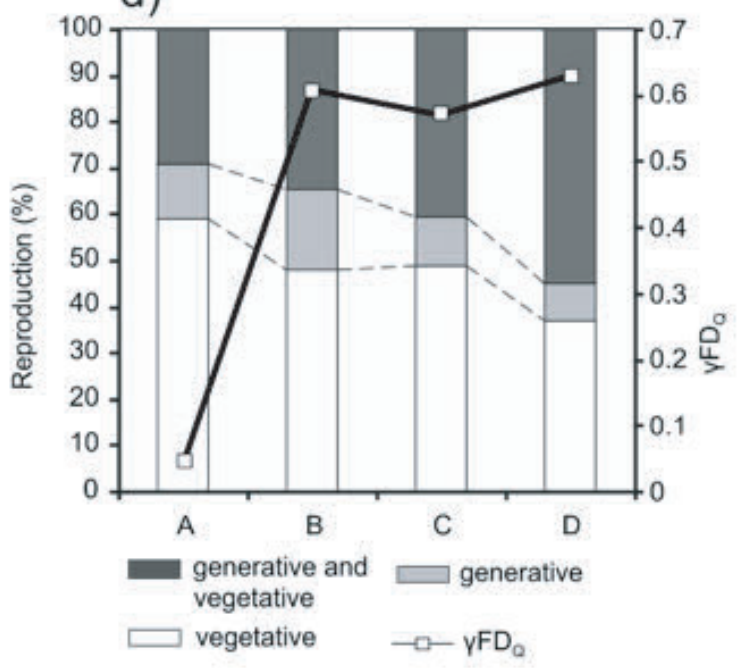

Fig. 2. The quantitative share of life history traits: plant life span (a), shoot growth form (b), leaf distribution along the stem (c), reproduction (d; left axis), and $\gamma \mathrm{FD}_{\mathrm{Q}}(\mathrm{d}$; right axis) for the four communities in analysis (A-D); see Fig. 1 for community's abbreviations. 
different in small unconnected and spatially isolated lakes and ponds (Oertli et al., 2002).

We have found higher $\beta$-diversity compared to $\alpha$ diversity. There are two reasons why high $\beta$-diversity has been observed. The first one is that small lakes differ in terms of their micro-site conditions (e.g., sandy, rock or peat bottom) and groundwater supply. The latter factor, as already mentioned, affects the concentration of inorganic carbon forms in water. The other is that species richness, especially in shallow lakes, is subject to stochastic events such as water fluctuation (Rørslett 1991; Szmeja, 1994) and by the dominance of species interactions over their dispersal dynamics (Chmara et al., 2013). Moreover, in submerged plant communities, the $\beta$ Simpson diversity index is lower than the $\alpha$-diversity level and is much smaller than the $\beta$ species richness (Tab. 2). Similar results have been obtained by de Bello et al. (2009) for plant communities in pastures along an altitude gradient in Spain. It is worth noting that the $\beta$ Simpson diversity index and $\beta$ species richness are different measures of species turnover among communities (Pavoine et al., 2004). The relatively low species turnover in moss carpets and the low $\beta$ Simpson diversity index means that this community is dominated by a stenoecious species $(S$. denticulatum). In moss carpet community low SD values were the result of the presence of a dominant $(S$. denticulatum) and a co-dominant ( $W$. exannulata) species. The abundance of other species is low.

For multi-trait functional diversity, we have found shifts on different diversity scales. On the $\alpha$ scale, functional diversity changes along acidity gradient. These results are consistent with a previous study of macrophyte communities (Chmara et al., 2015). Other studies have reported that environmental (Fu et al., 2014) and disturbance gradients (Biswas and Mallik, 2010) contribute to functional diversity. We have detected that beta functional diversity among communities was low,

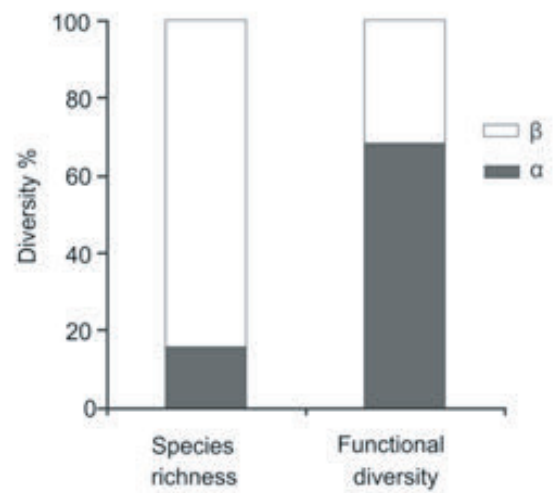

Fig. 3. Partitioning the diversity of species richness versus functional diversity into $\alpha$ - and $\beta$-diversity levels in lakes. constant and unrelated to acidity gradient. By contrast, functional turnover along the gradient has been found in grassland communities (Bernard-Vardier et al., 2013).

The quantitative distribution of single plant traits in a community changes along the gradient of decreasing water acidity; the proportion of all, non-evergreen perennials, anchored plants, plants with leaves along an orthotropic shoot and generative reproduction increases (Fig. 1). The variation in plant life span and leaf distribution may have a physiological basis. In moss carpets, there is a large share of species with leaves along a plagiotropic shoot, whereas in neutral lakes, plants with leaves along an orthotropic shoot dominate. Furthermore, the leaves exhibit an increasing ratio of surface area to unit biomass. These morphologies maximize the dissolved gases and flux of ions into and out of a leaf by maximizing the area per unit volume (Maberly and Madsen, 1998). Consequently, mosses attain predominance in an environment poor in inorganic forms of carbon, and form a species-poor community - moss carpets (Banaś et al., 2012).

In this study, we investigated how structural diversity relates to functional diversity of macrophyte communities. Our results have shown that species diversity within a community is low, whereas functional diversity is high (Fig. 3). This may mean that one of the attributes of plant communities in different environmental conditions is to preserve as high a level as possible of functional diversity. High $\alpha$-functional diversity and low functional turnover suggests that each macrophyte community has complementary functional groups serving as a 'functional buffer.' In the case of loss of species in a community, the functional buffer compensates for this loss of ecosystem functions. This biological mechanism can be explained on the basis of the insurance hypothesis (Yachi and Loreau, 1999). Moreover, we have found that functional and structural diversity exhibited opposing patterns along the water acidity gradient and across multiple spatial scales (Tab. 2; Figs. 1 and 3). A similar pattern has been found in a subtropical evergreen forest (Hu et al., 2014) and grassland communities (de Bello et al. 2009).

\section{CONCLUSIONS}

Relationships between structural and functional diversity of macrophyte communities in freshwater systems needs analysis of the diversity within ( $\alpha$ diversity) and between communities ( $\beta$-diversity). Our study has demonstrated a relatively constant $\beta$-functional diversity among macrophyte communities in lakes, unrelated to acidity. Structural diversity at the $\alpha$-, $\beta$ - and $\gamma$-diversity levels changes across acidity gradient. We conclude that structural and functional diversity in lakes had different opposing distribution patterns depending on 
the spatial scale. Future work and lake conservation might focus on the assessment of relationships between structural and functional diversity to other environmental and disturbance gradients.

\section{ACKNOWLEDGMENTS}

The paper is based on the results obtained in work under Project N N304 411638 funded by the Polish National Science Centre. We thank our colleagues for discussions and valuable comments on the manuscript. Hazel Pearson kindly corrected our English. We also thank the anonymous reviewers for useful suggestions on the first version of manuscript.

\section{REFERENCES}

Banaś K, Gos K, Szmeja J, 2012. Factors controlling vegetation structure in peatland lakes -Two conceptual models of plant zonation. Aquat. Bot. 96:42-47.

Bernard-Verdier M, Flores O, Navas ML, Garnier E, 2013. Partitioning phylogenetic and functional diversity into alpha and beta components along an environmental gradient in a Mediterranean rangeland. J. Veg. Sci. 24:877-889.

Biswas SR, Mallik AU, 2010. Disturbance effects on species diversity and functional diversity in riparian and upland plant communities. Ecology 91:28-35.

Bolpagni R, Laini A, Azzella MM, 2016. Short-term dynamics of submerged aquatic vegetation diversity and abundance in deep lakes. Appl. Veg. Sci. 19:711-723.

Bociąg K, Robionek A, Rekowska E, Banaś K, 2013. Effect of hydrodynamic disturbances on the biomass and architecture of the freshwater macroalga Chara globularis Thuill. Acta Bot. Gallica 160:149-156.

Boutin C, Keddy PA, 1993. A functional classification of wetland plants. J. Veg. Sci. 4:591-600.

Chappuis E, Gacia E, Ballesteros E, 2014. Environmental factors explaining the distribution and diversity of vascular aquatic macrophytes in a highly heterogeneous Mediterranean region. Aquat. Bot. 113:72-82.

Chmara R, Szmeja J, Ulrich W, 2013. Patterns of abundance and co-occurrence in aquatic plant communities. Ecol. Res. 28:387-395.

Chmara R, Szmeja J, Banaś K, 2014. Factors controlling the frequency and biomass of submerged vegetation in outwash lakes supplied with surface water or groundwater. Boreal Env. Res. 19:168-180.

Chmara R, Banaś K, Szmeja J, 2015. Changes in the structural and functional diversity of macrophyte communities along an acidity gradient in softwater lakes. Flora 216:57-64.

de Bello F, Lepš J, Sebastià MT, 2006. Variations in species and functional plants diversity along climatic and grazing gradients. Ecography 29:801-810.

de Bello F, Thuiller W, Lepš J, Choler P, Clement JC, Macek P, Sebastià MT, Lavorel S, 2009. Partitioning of functional diversity reveals the scale and extent of trait convergence and divergence. J. Veg. Sci. 20:475-486.
Díaz S, Cabido M, 2001. Vive la difference: plant functional diversity matters to ecosystem processes. Trends Ecol. Evol.16:646-655.

Eaton AD, Clesceri LS, Rice EW, Greenberg AE, 2005. Standard methods for the examination of water and wastewater, 21st ed. American Public Health Association, American Water Works Association and Water Environment Federation, Washington.

Fu H, Zhong J, Yuan G, Ni L, Xie P, Cao T, 2014. Functional traits composition predict macrophytes community productivity along a water depth gradient in a freshwater lake. Ecol. Evol. 9:1516-1523.

Gacia E, Chappuis E, Lumbreras A, Riera JL, Ballersteros E, 2009. Functional diversity of macrophyte communities within and between Pyrenean lakes. J. Limnol. 68:25-36.

Grime JP, 1977. Evidence for the existence of three primary strategies in plants and its relevance to ecological and evolutionary theory. Am. Nat. 111:1169-1194.

Hill MO, Šmilauer P, 2005. TWINSPAN for Windows Version 2.3. Centre for Ecology and Hydrology/University of South Bohemia, Huntingdon/České Budějovice.

Heino J, 2011. A macroecological perspective of diversity patterns in the freshwater realm. Freshwater Biol. 56:1703-1722.

$\mathrm{Hu}$ G, Jin Y, Liu J, Yu M, 2014. Functional diversity versus species diversity: relationships with habitat heterogeneity at multiple scales in a subtropical evergreen broad-leaved forest. Ecol. Res. 29:897-903.

Kleyer M, Bekker RM, Knevel IC, Bakker JP, Thompson K, Sonnenschein M, Poschlod P, vav Groenendael JM, Klmeš L, Klimešová, Klotz S, Rusch GM, Hermy M, Adriaens D, Boedeltje G, Bossuyt B, Dannemann A, Endels P, Götzenberger L, Hodgson JG, Jackel AK, Kühn I, Kunzmann D, Ozinga WA, Römermann C, Stadler M, Schlegelmilch J, Steendam HJ, Tackenberg O, Wilmann B, Cornelissen JHC, Eriksson O, Garnier E, Peco B, 2008. The LEDA Traitbase: A database of life-history traits of Northwest European flora. J. Ecol. 96:1266-1274.

Krienitz L, Nowak P, 2016. [Systematik der Charophyceae], p.17-27. In: Arbeitsgruppe Characeen Deutschlands Lehrstuhl für Ökologie der Universität (eds.), [Armleuchteralgen. Die Characeen Deutschlands].[Book in German]. Springer Spektrum Berlin.

Lepš J, de Bello F, Lavorel S, Berman S, 2006. Quantifying and interpreting functional diversity of natural communities: practical considerations matter. Presilia 78:481-501.

Levin SA, 1992. The problem of pattern and scale in ecology. Ecology.73:1943-1967.

Maberly SC, Madsen TV, 1998. Affinity for $\mathrm{CO}_{2}$ in relation to the ability of freshwater macrophytes to use $\mathrm{HCO}_{3}{ }^{-}$. Funct. Ecol. 12:99-106.

Madsen TV, Sand-Jensen K, 1991. Photosynthetic carbon assimilation in aquatic macrophytes. Aquat. Bot. 41:5-40.

Murphy KJ, 2002. Plant communities and plant diversity in softwater lakes of northern Europe. Aquat. Bot. 73:287-324.

Nicolet P, Biggs J, Fox G, Hodson MJ, Reynolds C, Whitfield M, Williams P, 2004. The wetland plant and macroinvertebrate assemblages of temporary ponds in England and Wales. Biol. Conserv. 120:261-278.

Nielsen SL, Sand-Jensen K, 1991. Variation in growth rates of submerged rooted macrophytes. Aquat. Bot. 39:109-120. 
Oertli B, Joye DA, Castella E, Juge R, Cambin D, Lachavanne JB, 2002. Does size matter? The relationship between pond area and biodiversity. Biol. Conserv. 104:59-70.

Pavoine S, Ollier S, Pontier D, 2004. Measuring diversity from dissimilarities with Rao's quadric entropy: are any dissimilarities suitable? Theor. Popul. Biol. 67:231-239.

Pedersen O, Sand-Jensen K, Revsbech NP, 1995. Dial pulses of $\mathrm{O}_{2}$ and $\mathrm{CO}_{2}$ in sandy lake sediments inhabited by Lobelia dortmanna. Ecology 76:1536-1545.

Petchey OL, Gaston KJ, 2002. Functional diversity (FD), species richness and community composition. Ecol. Lett. 5:402-411.

Petchey OL, Gaston KJ, 2006. Functional diversity: back to basics and looking forward. Ecol. Lett. 9:741-758.

Pulido C, Sand-Jensen K, Lucassen ECHET, Roelofs JGM, Brodersen KP, Pedersen O, 2012. Improved prediction of vegetation composition in NW European softwater lakes by combining location, water and sediment chemistry. Aquat. Sci.74:351-360.

Pulido C, Riera JL, Ballesteros E, Chappuis E, Gacia E, 2015. Predicting aquatic macrophyte occurrence in soft-water oligotrophic lakes (Pyrenees mountain range). J. Limnol. 74:143-154.

Ricklefs RE, 2004. A comprehensive framework for global patterns in biodiversity. Ecol. Lett. 7:1-15.

Ricotta C, 2005. A note on functional diversity measures. Basic Appl. Ecol. 6:479-486.

Riis T, Olsen B, Katborg CK, Christoffersen KS, 2010. Growth rate of an aquatic bryophyte (Warnstorfia fluitans (Hedw.) Loeske) from a High Arctic lake: Effect of nutrient concentration. Arctic 63:100-106.

Rørslett B, 1991. Principal determinants of aquatic macrophytes richness in northern European lakes. Aquat. Bot. 39:173-193.
Scheffer M, van Geest GJ, 2006. Small habitat size and isolation can promote species richness: second-order effects on biodiversity in shallow lakes and ponds. Oikos 112:227-231.

Søndergaard M, Sand-Jensen K, 1979. Carbon uptake by leaves and roots of Littorella uniflora (L.) Aschers. Aquat. Bot. $6: 1-12$.

Szmeja J, 1987. The ecology of Lobelia dortmanna L. 1. The plasticity of individuals within a constant depth interval in oligotrophic lakes. Ekol. Pol.-Pol. J. Ecol. 35:497-522.

Szmeja J, 1994. An individual's status in populations of isoetid species. Aquat. Bot. 48:203-224.

Szmeja J, 2010. Changes in the aquatic moss Sphagnum denticulatum Brid. population abundance in a softwater lake over a period of three years. Acta Soc. Bot. Pol. 79:167-173.

Szmeja J, Gałka A, 2008. Phenotypic responses to water flow and wave exposure in aquatic plants. Acta Soc. Bot. Pol. 77:59-65.

The Plant List, 2013. The Plant List ver. 1.1. Accessed on: 1 February 2017. Available from: http://www.theplantlist.org/

Veech JA, Summerville KS, Crist TO, Gering JC, 2002. The additive partitioning of species diversity: recent revival of an old idea. Oikos 99:3-9.

Vestergaard O, Sand-Jensen K, 2000. Alkalinity and trophic state regulate aquatic plant distribution in Danish lakes. Aquat. Bot. 67:85-107.

Whittaker RH, 1975. Communities and ecosystems. Macmillan, New York: 352 pp.

Willby NJ, Abernethy VJ, Demars BOL, 2000. Attribute-based classification of European hydrophytes and its relationship to habitat utilization. Freshwater Biol. 43:43-74.

Yachi S, Loreau M, 1999. Biodiversity and ecosystem productivity in a fluctuating environment: the insurance hypothesis. P. Natl. Acad. Sci. USA 96:1463-1468. 